Article

\title{
Effect of the Albumin Corona on the Toxicity of Combined Graphene Oxide and Cadmium to Daphnia magna and Integration of the Datasets into the NanoCommons Knowledge Base
}

\author{
Diego Stéfani T. Martinez ${ }^{1,2,3, *}$, , Gabriela H. Da Silva ${ }^{1}$, Aline Maria Z. de Medeiros ${ }^{1,2,3}$, \\ Latif U. Khan 1,2,4 ${ }^{\mathbb{D}}$, Anastasios G. Papadiamantis ${ }^{2,5}$ and Iseult Lynch ${ }^{2, *(\mathbb{D})}$ \\ 1 Brazilian Nanotechnology National Laboratory (LNNano), Brazilian Center for Research in Energy and \\ Materials (CNPEM), Campinas 13083-100, Sao Paulo, Brazil; gabriela.silva@lnnano.cnpem.br (G.H.D.S.); \\ aline.zigiotto@usp.br (A.M.Z.d.M.); latifullah.khan@sesame.org.jo (L.U.K.) \\ 2 School of Geography, Earth and Environmental Sciences, University of Birmingham, \\ Edgbaston, Birmingham B15 2TT, UK; A.Papadiamantis@bham.ac.uk \\ 3 Center of Nuclear Energy in Agriculture (CENA), University of Sao Paulo (USP), \\ Piracicaba 13416-000, Sao Paulo, Brazil \\ 4 Synchrotron-Light for Experimental Science and Applications in the Middle East (SESAME), \\ Allan 19252, Jordan \\ 5 NovaMechanics Ltd., Nicosia 1065, Cyprus \\ * Correspondence: diego.martinez@lnnano.cnpem.br (D.S.T.M.); i.lynch@bham.ac.uk (I.L.)
}

Received: 1 September 2020; Accepted: 24 September 2020; Published: 29 September 2020

check for updates

\begin{abstract}
In this work, we evaluated the effect of protein corona formation on graphene oxide (GO) mixture toxicity testing (i.e., co-exposure) using the Daphnia magna model and assessing acute toxicity determined as immobilisation. Cadmium $\left(\mathrm{Cd}^{2+}\right)$ and bovine serum albumin (BSA) were selected as co-pollutant and protein model system, respectively. Albumin corona formation on GO dramatically increased its colloidal stability (ca. 60\%) and $\mathrm{Cd}^{2+}$ adsorption capacity (ca. 4.5 times) in reconstituted water (Daphnia medium). The acute toxicity values (48 h-EC 50 ) observed were $0.18 \mathrm{mg} \mathrm{L}^{-1}$ for $\mathrm{Cd}^{2+}$-only and 0.29 and $0.61 \mathrm{mg} \mathrm{L}^{-1}$ following co-exposure of $\mathrm{Cd}^{2+}$ with $\mathrm{GO}$ and BSA@GO materials, respectively, at a fixed non-toxic concentration of $1.0 \mathrm{mg} \mathrm{L}^{-1}$. After coronation of GO with BSA, a reduction in cadmium toxicity of $110 \%$ and $238 \%$ was achieved when compared to bare GO and $\mathrm{Cd}^{2+}$-only, respectively. Integration of datasets associated with graphene-based materials, heavy metals and mixture toxicity is essential to enable re-use of the data and facilitate nanoinformatics approaches for design of safer nanomaterials for water quality monitoring and remediation technologies. Hence, all data from this work were annotated and integrated into the NanoCommons Knowledge Base, connecting the experimental data to nanoinformatics platforms under the FAIR data principles and making them interoperable with similar datasets.
\end{abstract}

Keywords: nanoecotoxicity; co-exposure; nanosafety; harmonisation; nanoinformatics

\section{Introduction}

Graphene oxide (GO) is a promising carbon-based nanomaterial for the remediation and detection of environmental pollutants, such as pesticides and heavy metals, from contaminated water. However, it is imperative to evaluate the toxicity and the potential risks associated with these emerging materials from the nanotechnology industry [1]. Proteins interact with nanomaterials by forming a molecular coating commonly called the protein corona, modulating their attachment to and internalisation by cells 
and their subsequent toxicity [2-4]. This protein coating impacts critically on the nanomaterial surface chemistry properties by modulating its interactions with biological and environmental systems [5]. Bovine serum albumin (BSA) is a globular protein $(66.5 \mathrm{kDa})$ which has been studied as a model biomolecule in nanobiotechnology, nanotoxicology and environmental nanoscience. Liu et al. (2010) demonstrated that BSA is a universal "adhesive" protein facilitating development of GO hybrid materials decorated with metallic nanoparticles [6]. Recently, it was demonstrated that BSA covalently bound to GO is a very interesting hybrid material for removal of uranium ions from seawater [7] and to produce filter membranes for metallic ion removal (i.e., $\mathrm{AuCl}_{4}{ }^{-}, \mathrm{Co}^{2+}, \mathrm{Cu}^{2+}, \mathrm{Fe}^{2+}$ ) from aqueous solutions [8]. In addition, BSA has been considered as a model protein for assessing the fate of graphene oxide and other nanomaterials in the aquatic environment and colloidal nano-interactions with dissolved organic matter, such as humic substances [9-12]. Recently, Sun et al. (2020) demonstrated that both protein structure and concentration are determinants for GO stability in aquatic environments, and that GO lateral size and solution chemistry are also crucial factors [13]. Despite these findings, there is a lack of systematic understanding of the protein corona formation on GO and its impacts on aquatic systems, such as ecotoxicological effects during combined exposure with other pollutants [14].

Data management is one of the most neglected practices in every day scientific research and is typically not implemented, if ever, until very late in experimental practice when valuable information and metadata may have been lost. This has a significant impact on experimental reproducibility, and data completeness and re-usability, especially when the increasing complexity of experimental and analytical workflows are considered [15]. This is especially important as the emergence of nanoinformatics requires a high volume of interoperable high-quality data [16-18]. As stated in the EU-US Nanoinformatics Roadmap 2030, datasets need to be enriched with sufficient metadata and annotated with established ontologies to allow easy integration with other data and re-use. Such integrated analysis can lead to the uncovering of hidden pattern and relationships, as demonstrated by Labouta et al. (2019), following the combination and meta-analysis of 93 peer-reviewed publications on the cytotoxicity of organic and inorganic nanomaterials [19]. Papadiamantis et al. discuss the role of metadata for nanosafety and nanoinformatics further in this special issue.

Data interoperability is especially important in a regulatory context, where standardised guidelines (e.g., OECD, ISO) need to be followed during experimental practice and becomes even more prominent as computational tools and workflows come into the picture. As a result, protocol and medium harmonisation are of the utmost importance as several cytotoxicity meta-analysis studies have stressed and demonstrated a significant correlation between the type of assay and medium used and the resulting hazardous effects [20-22]. To achieve this, the Horizon 2020 e-infrastructure project NanoCommons (www.nanocommons.eu) has been developing a cloud-based Knowledge Base, which links nano-related databases, and provides data curation and storage solutions linking information about the nanomaterials, their medium or environmental conditions and the overall test conditions to the resulting effect data, enabling tracking of changes to the particles over the experimental timeframe. NanoCommons offers a wide range of data management workflows covering the entire data lifecycle, from experimental planning up to publication and online data availability and accessibility. These workflows contain the implementation and use of electronic laboratory notebooks (ELNs), standardised templates to capture data and metadata as they are produced and semantic annotation using established ontologies. These practices facilitate and streamline experimental research, allow full implementation of the FAIR (findable, accessible, interoperable and reusable) data principles [23], promote innovation, risk assessment and governance of nanomaterials and support the sustainability of the nanotechnology and the advanced materials community, where graphene oxide is a leading contender.

Mixture or combined pollutant toxicity is an important issue in ecotoxicology and regulation of mixtures of chemicals [24,25]. In the environment, nanomaterials will interact with different types of co-pollutants, incurring joint toxicological effects [14,26,27]. Graphene oxide interacts with environmental pollutants (e.g., pesticides, surfactants, dyes and heavy metals) by modulating the 
toxicity of these toxic compounds against several biological models, including bacteria, cells, plants and fish [28]. Considering the Daphnia magna model, it was demonstrated that carbon nanomaterials, such as single walled carbon nanotubes, can increase the acute toxicity of metals such as $\mathrm{Cu}^{2+}$ and $\mathrm{Cd}^{2+}$ following co-exposure scenarios $[29,30]$. Other reports have indicated that graphene oxide can mitigate toxicity of these heavy metal ions on this aquatic model organism [31,32]. However, a critical research gap currently is the absence of standardised protocols for toxicity assessment of nanomaterials and chemical mixtures that takes account of the unique features of nanomaterials such as their corona formation and environmental ageing which may influence their adsorption capacity for co-pollutants $[33,34]$. Therefore, it is difficult to compare the literature data reports published so far involving nanomaterials, heavy metals and D. magna toxicity. The annotation of experimental data into nanoinformatics platforms (i.e., NanoCommons) is a promising alternative to overcome this current scenario, supporting harmonised protocols and comparable scientific data and identification of differences between datasets based on their exposure conditions. Additionally, this approach has the potential to reduce the cost and time required for experimental research thereby supporting regulation [18].

In this work, we evaluated the effects of albumin corona graphene oxide (BSA@GO) on cadmium toxicity to D. magna. BSA-corona formation on the graphene oxide surface acts by enhancing the adsorption capacity of cadmium and thus reducing its availability and toxicity to D. magna (mitigation effect) during co-exposure experiments. These findings suggest that this could be a very interesting approach to design non-toxic GO-BSA hybrid materials for water quality monitoring and environmental remediation technologies. This is the first report of the influence of protein corona formation on acute mixture toxicity in the D. magna model. Finally, all experimental data from this work were annotated and integrated into the NanoCommons platform using harmonised ontological terms associated with the environmental health and safety aspects of nanomaterials and the full dataset is available for further analysis and re-use.

\section{Materials and Methods}

\subsection{Data Management}

The data management plan (DMP) was based on the FAIR principles and the need for the data and metadata to be digitised and semantically annotated as soon as they are generated. Initially, a detailed mapping (instance map) of the experimental workflow was drawn using Lucidchart [35]. The whole experiment was divided into instances, i.e., important experimental steps where the extrinsic characteristics of the nanomaterials might change, each one containing the specific information needed to fully describe the nanomaterial and its surroundings. This allowed the experimental team to have a complete picture of the entire workflow and to identify any gaps that may exist. The instance map also acts as a graphical abstract for the dataset produced. For data and metadata capturing the SciNote electronic laboratory notebook (ELN) was used [36]. Based on the instance map generated for the dataset the necessary protocols were gathered and imported into SciNote and linked with the respective experimental workflows. Similarly, for each experimental step the respective data curation templates were drawn-up and compiled into SciNote for the data capture to take place as the data are generated. Furthermore, all used terms were semantically annotated, using mainly the eNanoMapper ontology (ENM) [37] and all ontological IDs were linked to the SciNote ELN and the produced datasets. For terms that were not included in ENM, relevant terms were identified from other ontologies (e.g., NPO, CHEBI and CHMO). Following data capture, the produced datasets, along with all relevant metadata (protocols, assays, instruments types and settings), were automatically extracted and sent for upload into the NanoCommons Knowledge Base (https://ssl.biomax.de/nanocommons/). 


\subsection{Synthesis of the Graphene Oxide}

Natural graphite flakes were purchased from Sigma-Aldrich (St. Louis, MO, USA). The graphene oxide used in this work was synthesized according to Hummer's method with modifications [38]. Briefly, $5.0 \mathrm{~g}$ of graphite and $3.75 \mathrm{mg}$ of $\mathrm{NaNO}_{3}$ were mixed in a round bottom flask containing $370 \mathrm{~mL}$ of $\mathrm{H}_{2} \mathrm{SO}_{4}$ for $20 \mathrm{~min}$ under magnetic stirring in an ice bath. $22.5 \mathrm{~g}$ of $\mathrm{KMnO}_{4}$ in $300 \mathrm{~mL}$ of ultrapure water was slowly added and the mixture reaction was kept stirring for $72 \mathrm{~h}$ at room temperature. Then, the mixture was stirred for another $1 \mathrm{~h}$ at $95^{\circ} \mathrm{C}$. After the temperature reduced to $60^{\circ} \mathrm{C}, \mathrm{H}_{2} \mathrm{O}_{2}(15 \mathrm{~mL}$, $30 \%$ ) was added and the solution was left to stand overnight at room temperature. The mixture was centrifuged at $6000 \mathrm{rpm}$ for $15 \mathrm{~min}$ and rinsed with $1.0 \mathrm{~L}$ of an aqueous solution of $\mathrm{H}_{2} \mathrm{SO}_{4}(3 \%)$ and $\mathrm{H}_{2} \mathrm{O}_{2}(0.5 \%)$ to remove oxidant ions and inorganic impurities. The resulting product was dialyzed against ultrapure water for $72 \mathrm{~h}$. The graphene oxide dispersion was lyophilized and stored in a glass desiccator at room temperature.

\subsection{Characterisation of Graphene Oxide}

The size distribution of the GO flakes was measured by atomic force microscopy (AFM) on a Multimode 8 microscope with a Nano Scope 5 controller with peakforce tapping (Bruker, MA, USA). The GO dispersion ( $10 \mu \mathrm{g} \mathrm{mL} \mathrm{mL}^{-1}$ ) was dropped onto a clean mica surface and dried in a desiccator overnight at room temperature. Then the GO flakes were measured using a silicon tip (tapping mode) with nominal resonance frequency of $320 \mathrm{kHz}$ and nominal force constant of $42 \mathrm{~N} \mathrm{~m}^{-1}$. Thermogravimetric analysis (TGA) was performed for the GO on a STA 449F3 Jupiter@ instrument (NETSCH, Deutschland, Germany), employing a heating rate of $110^{\circ} \mathrm{C} \mathrm{mim}^{-1}$ (from 25 to $750{ }^{\circ} \mathrm{C}$ ) with a synthetic air flow of $50 \mathrm{~mL} \mathrm{~min}{ }^{-1}$. X-ray diffraction analysis (XRD) to structurally characterise the GO was performed on an Advanced Eco D8 XDR instrument (Bruker, MA, USA), using a Cu K $\alpha 1$ radiation $(\lambda: 1.5406 \AA)$ at $40 \mathrm{kV}$ in the range of $2 \theta=5-90^{\circ}$. For surface chemistry analysis, the GO was characterised using attenuated total reflection Fourier infrared spectroscopy (ATR-FTIR, Nicolet ${ }^{\mathrm{TM}}$, Thermo Scientific, MA, USA); and X-ray photoelectron spectroscopy (XPS, K-alpha, Thermo Scientific, MA, USA), applying a pass energy of $200 \mathrm{eV}$ and $50 \mathrm{eV}$ to obtain the survey and high-resolution spectra, respectively. Raman confocal spectroscopy was employed for structural defects characterisation in GO with laser $532 \mathrm{~nm}$ (Horiba ${ }^{\circledR}$, Kyoto, Japan).

\subsection{Preparation and Characterisation of BSA@GO Material}

Bovine serum albumim (BSA, 98\% purity) was obtained from Sigma-Aldrich (St. Louis, MO, USA). The GO stock-dispersion ( $20 \mathrm{mg}$ in $20 \mathrm{~mL}$ of ultrapure water) was prepared using an ultrasound bath (Cole-Parmer, CPXH $40 \mathrm{~Hz}$, IL, USA) for $60 \mathrm{~min}$. A total of $100 \mu \mathrm{L}$ of GO stock-dispersion was incubated with $900 \mu \mathrm{L}$ of BSA $\left(1.0 \mathrm{mg} \mathrm{mL}^{-1}\right)$ in phosphate buffer saline (PBS, $\mathrm{pH}$ 7.4) solution for $60 \mathrm{~min}$ at $37^{\circ} \mathrm{C}$ in a thermoblock system (Thermomixer C, Eppendorf, Hamburg, Germany). After this incubation period, the albumin corona coated graphene oxide (BSA@GO) was obtained by centrifugation at $14,000 \mathrm{rpm}$ for $60 \mathrm{~min}$ at $4.0^{\circ} \mathrm{C}$, followed by three washing steps with PBS buffer. The final pellet (BSA@GO sample) was re-suspended in ultrapure water for $\mathrm{Cd}^{2+}$ adsorption, dispersion stability and toxicity studies. This sample was also dried under speed-vacuum (SpeedDry, Christ, Osterode am Harz, Germany) for material characterisation in the solid-state, employing ATR-FTIR and TGA analyses as previously described (see item 2.3.) For AFM analysis, $10 \mu \mathrm{g} \mathrm{mL}^{-1}$ of BSA@GO in ultrapure water was dropped onto a clean mica surface and dried in a desiccator overnight at room temperature. The surface roughness of the material was monitored in tapping mode with nominal resonance frequency of $320 \mathrm{kHz}$ and nominal force constant of $42 \mathrm{~N} \mathrm{~m}^{-1}$ (Nano Scope 5, Bruker, MA, USA). Scanning electron microscopy (SEM, FEI Quanta 650 FEG, Hillsboro, OR, USA) was also performed, but the results were poor and did not provide any useful information. 


\subsection{Dispersion Stability Studies}

The colloidal dispersion stability (agglomeration and deposition behaviour) of GO and BSA@GO was monitored by UV-VIS spectroscopy (at $400 \mathrm{~nm}$ ) in reconstituted water from 0 to $72 \mathrm{~h}$ (incubation time). Firstly, dispersions (10 mL) of GO and BSA@GO materials at $10 \mathrm{mg} \mathrm{L}^{-1}$ were prepared in triplicate. For UV-VIS monitoring, we collected the supernatant $(100 \mu \mathrm{L})$ following settling at each interval of time and measured the absorbance at $400 \mathrm{~nm}$ (Spark ${ }^{\circledR}$ microplate reader, Tecan, Männedorf, Switzerland). The average hydrodynamic size and surface charge (zeta-potential) of both samples were analysed by dynamic light scattering (DLS) and electrophoretic light scattering (ELS) on a Zetasizer Nano ZS equipment (Malvern Instruments, Malvern, UK). For DLS/ELS measurements, $1.0 \mathrm{~mL}$ of sample was prepared and kept in the appropriate cuvette and used to obtain the time-resolved hydrodynamic diameter (HD), polydispersity index (PdI) and zeta-potential values in ultrapure water and reconstituted water. These experiments were performed in triplicate under static conditions at $20^{\circ} \mathrm{C}$.

\subsection{Cadmium Adsorption Experiments}

Cadmium chloride $\left(\mathrm{CdCl}_{2}, 99.9 \%\right.$ purity) was obtained from Sigma-Aldrich (St. Louis, MO, USA). The adsorption capacity of $\mathrm{Cd}^{2+}$ onto GO and BSA@GO materials was verified with adsorption experiments. Adsorption isotherms were obtained by varying the initial concentration of $\mathrm{Cd}$ (1.0-10 $\left.\mathrm{g} \mathrm{L}^{-1}\right)$ at a fixed concentration of both graphene-based materials $\left(10 \mathrm{mg} \mathrm{L}^{-1}\right)$. Firstly, the mixed solutions of GO and BSA@GO and $\mathrm{Cd}^{2+}$ in reconstituted water were prepared and kept for $72 \mathrm{~h}$ under orbital mixing (20 rpm) at $20^{\circ} \mathrm{C}$ (Stuart ${ }^{\circledR}$ Rotator SB3, Cole-Parmer Vernon Hills, IL, USA). Then, the supernatant was collected by centrifugation for $30 \mathrm{~min}$ at 14,000 rpm (Eppendorf 5430R, Hamburg, Germany). The residual $\mathrm{Cd}^{2+}$ ion concentrations in the supernatants were measured by inductively coupled plasma mass spectrometry (ICP-MS; Nexion 300x PerkinElmer, MA, USA). All adsorption experiments were performed in independent triplicates. The total amount of $\mathrm{Cd}^{2+}$ adsorbed at adsorption equilibrium was calculated by the equations:

$$
\begin{gathered}
\text { Adsorption (\%) }=\frac{C_{0}-C_{e}}{C_{0}} \times 100 \% \\
Q_{e}=\frac{\left(C_{0}-C_{e}\right) \times V}{W}
\end{gathered}
$$

where $Q_{e}$ is adsorption capacity $\left(\mathrm{mg} \mathrm{mg}^{-1}\right) ; C_{o}$ and $C_{e}$ are the ion concentrations at the beginning and end of the adsorption assay ( $\left.\mathrm{mg} \mathrm{L}^{-1}\right) ; V$ is the solution volume (L); and $W$ is the mass of adsorbent $(\mathrm{g})$. The Freundlich model (Equation (3)) was used to describe the adsorption behaviour of $\mathrm{Cd}^{2+}$ onto GO and BSA@GO materials:

$$
\log Q_{e}=\log K+\left(\frac{1}{n}\right) \log C_{e}
$$

where $K\left(\mathrm{mg} \mathrm{g}^{-1}\right)$ is the adsorption capacity constant from the Freundlich model and $n$ is the Freundlich linearity index and is related to the adsorption intensity. The numerical values were calculated by linear fit of the respective plot using the intercept and slope value, respectively.

\subsection{Toxicity Assays with Daphnia Magna}

The D. magna culture was maintained at the Brazilian Nanotechnology National Laboratory (LNNano/CNPEM, Campinas, SP, Brazil). The culture of organisms and acute toxicity testing were conducted according to the Brazilian Technical Standards Association guideline ABTN NBR 12713:2016. $D$. magna cultivation and all toxicity experiments were performed under controlled temperature $\left(20 \pm 1.0^{\circ} \mathrm{C}\right)$ and photoperiod (12:12h, light:dark) in biological incubators (B.O.D., Eletrolab EL212, Sao Paulo, Brazil).

Five D. magna neonates ( $<24 \mathrm{~h}$ old) were exposed to the materials in $10 \mathrm{~mL}$ test solution for 24,48 and $72 \mathrm{~h}$. For the acute toxicity determination, different concentration ranges of $\mathrm{Cd}^{2+}$ 
(0.1-2.1 mg L L $\mathrm{mg}^{-1}$, GO (1.0-100 mg L L $\mathrm{m}^{-1}$, BSA (1.0-100 mg L $\left.\mathrm{m}^{-1}\right)$, and BSA@GO (1.0-100 mg L $\left.\mathrm{m}^{-1}\right)$ were evaluated. The acute toxicity of mixtures was evaluated using the following experimental design. Low concentrations of GO and BSA@GO showing no mortality (i.e., 0.1, 1.0 and $10 \mathrm{mg} \mathrm{L}^{-1}$ ) were mixed with $\mathrm{Cd}$ at concentrations ranging from 0.1 to $2.1 \mathrm{mg} \mathrm{L}^{-1}$. The concentration of $\mathrm{Cd}^{2+}$ in reconstituted water (stock-solution) was evaluated using inductively coupled plasma optical emission spectrometry (ICP-OES, Perkin Elmer, MA, USA). The chemical composition of the reconstituted water is described in the supplementary materials. The parameters for the reconstituted water used were $\mathrm{pH}(7.6-8.0)$ and hardness (175-225 $\mathrm{mg} \mathrm{L}^{-1}$ of $\left.\mathrm{CaCO}_{3}\right)$.

The conditioned medium for toxicity testing (CMT) was prepared by incubating 500 neonates (less than $24 \mathrm{~h}$ old) in $1.0 \mathrm{~L}$ of reconstituted water for $72 \mathrm{~h}$. After this incubation period, the daphnids were removed and this medium was used in the toxicity testing. The total protein content in the CMT was quantified by Bradford assay (Sigma-Aldrich, MO, USA). For protein quantification, $200 \mathrm{~mL}$ of CMT was concentrated (to the final volume of $1.0 \mathrm{~mL}$ ) using Centricon tubes (Amicon Ultra-15 Centrifugal Filter Unit, Millipore, MA, USA).

\subsection{Statistical Analysis}

PriProbit software was used to obtain the $\mathrm{EC}_{50}$ values via Probit analysis including $95 \%$ confidence limits (CL) by regression analysis according to Sakuma [39]. The concentration-response curve (Sigmoidal fitting) was obtained with Origin-Pro 2018 software.

\section{Results and Discussion}

There is a clear need to collect the physicochemical and toxicological nanomaterial data in consistently organised electronic datasets which can be integrated into nanoinformatics platforms to support predictive models toward data-driven approaches in nanotechnology and nanosafety regulation $[17,18,40,41]$. Moreover, nanomaterials have a complex and versatile nature, which leads to continuous transformations not only when exposed to environmental and biological media, but also during storage [42,43]. These transformations lead to substantial challenges for the risk assessment of nanomaterials, which become greater the more complex the study systems are (e.g., functionalisation, corona formation, ageing and mixtures). The difficulty of handling and studying nanomaterials under environmentally or biologically relevant conditions leads scientists to design, implement and perform complex experimental workflows. These usually contain several steps of increasing complexity requiring careful planning of the data and metadata that are required to be captured and can lead to gaps in the produced datasets, which in turn result in difficulties during analysis and decrease the data's interoperability and reusability potential. To overcome such risks, a detailed data management plan (DMP) needs to be put together and implemented from the experimental design phase. Including a visual representation of the entire experimental procedure is recommended (see Figure 1), which will help to identify gaps and facilitate the implementation of pre-annotated, FAIR and detailed (meta)data templates that can be used during everyday experimental practice.

Experimental visualisation (Figure 1) allowed us to gather all the information needed to implement a detailed SciNote workflow, populate all the required (meta)data and create a complete high-quality and interoperable dataset. The dataset was then extracted and sent to the NanoCommons Knowledge Base (https://ssl.biomax.de/nanocommons/) for uploading and further exploitation (e.g., integration into computational workflows). To our knowledge, this is the first demonstration of the potential application of nanoinformatics data management tools linked to graphene-based materials, focusing on heavy metal adsorption and mixture toxicity in the D. magna model. 


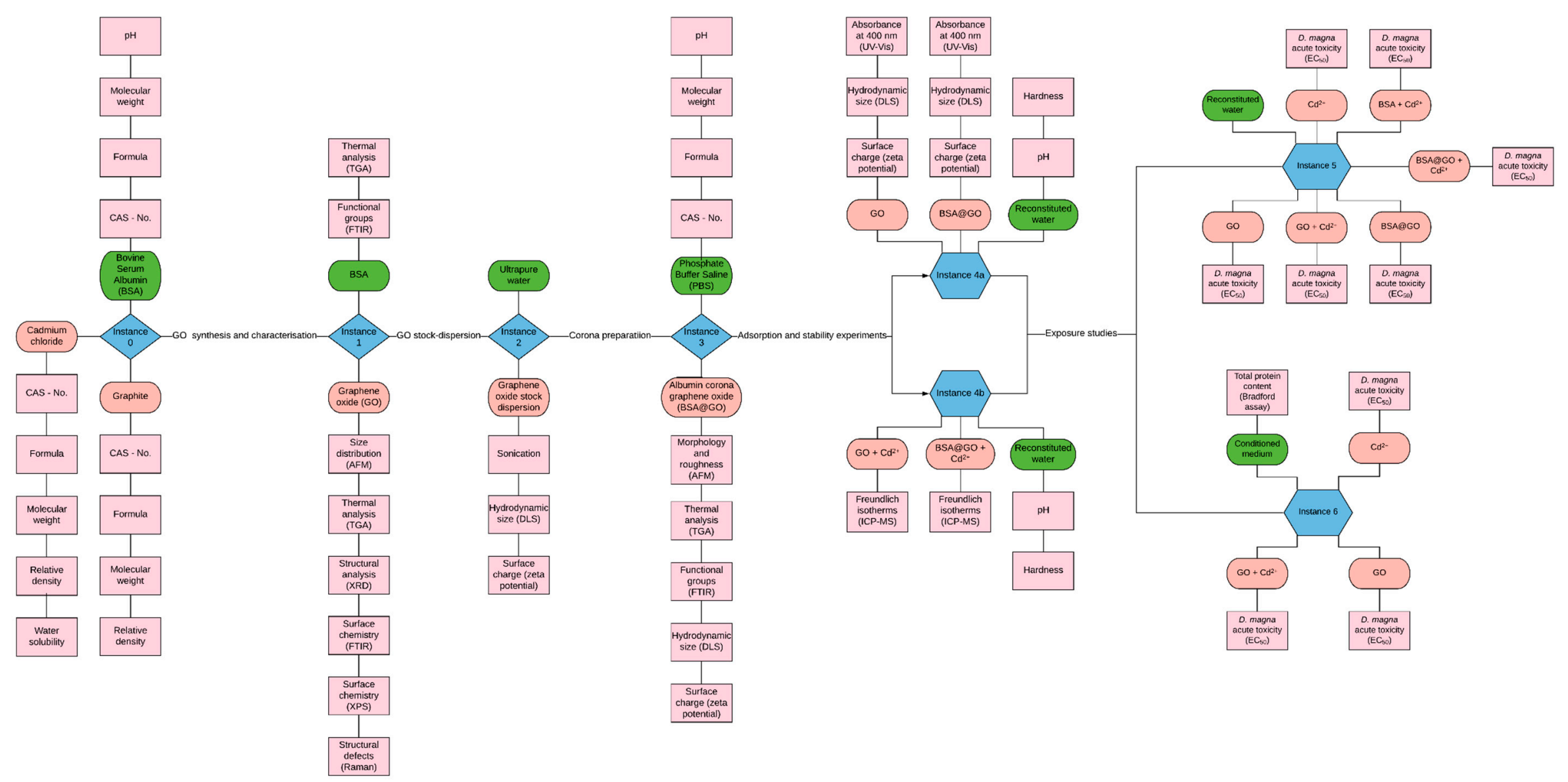

Figure 1. Experimental workflow used for integration of the datasets into the NanoCommons Knowledge Base. Note that the characteristics of each of the components (nanomaterials, media, proteins and co-pollutants) are included as part of the overall dataset and each instance represents a change to the overall system (e.g., a dispersion step, a corona formation step etc.). 
The synthesis of graphene oxide is the starting point for its technological applications and toxicity assessment. Hummer's method is commonly used to produce graphene oxide by chemical exfoliation of graphite, and it has been applied to large-scale production and applications of GO-based materials. The final graphene oxide material quality is totally dependent on the synthetic method employed [44]. In addition, the physico-chemical characterisation of nanomaterials is a fundamental step toward toxicity assessment and environmental applications. Therefore, the GO produced was well-characterized by AFM, XRD, Raman, UV-VIS, and XPS techniques (Figure S1, supplementary information). The morphological characterisation by AFM confirmed the single layer aspect ( $<1.5 \mathrm{~nm}$ thickness) of the GO material produced, and the flake size distribution ranges from 18 to $308 \mathrm{~nm}$, with a mean value of $141 \mathrm{~nm}$. The XRD analysis confirmed the very characteristic diffraction peak of graphene oxide $\left(2 \theta=10.59^{\circ}\right)$ that was obtained in the range from $5^{\circ}$ to $35^{\circ}(2 \theta)$. Raman spectroscopy is a powerful technique to evaluate the structural defects in carbon nanomaterials, presenting two typical bands for these types of materials. The $\mathrm{G}$ band, located at $1591 \mathrm{~cm}^{-1}$, is the result of $\mathrm{Csp}^{2}$ vibration of carbon atoms. The $\mathrm{D}$ band, located at $1331 \mathrm{~cm}^{-1}$, is related to structural defects. Thus, the ratio of the intensity of D-band $\left(\mathrm{I}_{\mathrm{D}}\right)$ to the intensity of $\mathrm{G}$-band $\left(\mathrm{I}_{\mathrm{G}}\right)$ was estimated as $\mathrm{I}_{\mathrm{D}} / \mathrm{I}_{\mathrm{G}}=0.85$. The UV-VIS absorption spectrum exhibits a peak at $230 \mathrm{~nm}$, that is characteristic of $\pi-\pi^{*}$ transitions of C-C aromatic bonds. The chemical composition of the GO surface was investigated by X-ray photoelectron spectroscopy (XPS). The survey spectrum shows the presence of carbon $(\sim 68 \%)$ and oxygen $(\sim 32 \%)$. The deconvoluted C1s spectrum shows the presence of oxygen functional groups as epoxy/hydroxyl $(\mathrm{C}-\mathrm{O})(52 \%)$, carboxyl/esters $(\mathrm{C}=\mathrm{O})(9.4 \%)$ and $\pi-\pi^{*}$ transitions $(4.2 \%)$, besides the graphitic/aromatic carbon $\left(\mathrm{Csp}^{2}\right)(5.7 \%)$ and aliphatic carbon $\left(\mathrm{Csp}^{3}\right)(28 \%)$. Collectively, these results confirm the synthesis of GO material with similar properties to other graphene oxide samples commonly used for nanotoxicology and environmental applications [45-47].

For protein corona characterisation, a comparative study between bare GO and BSA@GO was performed exploring AFM, FTIR and TGA as complementary techniques (Figure 2). AFM imaging revealed that the thickness of the GO flakes was ca. $1.0 \mathrm{~nm}$ (Figure 2A). AFM has also applied to study the interaction of proteins with $\mathrm{GO}$, and it allows visualization of protein corona formation by measuring the surface roughness and thickness of the GO-protein hybrid materials. The BSA@GO material showed a higher surface roughness $(1.22 \pm 0.26 \mathrm{~nm})$ when compared to bare GO $(0.24 \pm 0.01 \mathrm{~nm})$, indicating the presence of albumin adsorbed onto the GO surface (Figure 2B). Similar results have been reported in the literature for other model proteins, such as immunoglobulins and peroxidase, as well as to mixture of proteins (i.e., foetal bovine serum) associated with graphene oxide [48].

The TGA and FTIR analysis of GO and BSA@GO were performed to evaluate the thermal behaviour and functional groups on these materials. The FTIR spectrum (Figure 2C) of GO shows the broad absorption band at $\sim 3403 \mathrm{~cm}^{-1}$, attributed to the stretching vibration of $\mathrm{O}-\mathrm{H}$. The strong absorption band at $1728 \mathrm{~cm}^{-1}(\nu \mathrm{C}=\mathrm{O})$ indicates the presence of carboxylic acid groups in the graphene oxide flakes. In addition, the absorption peak at $1625 \mathrm{~cm}^{-1}$ corresponds to the stretching vibration of $\mathrm{C}=\mathrm{C}$ and that at $\sim 1060 \mathrm{~cm}^{-1}$ is assigned to the $v \mathrm{C}-\mathrm{O}$ (primary alcohol) in the GO lattice. It is noteworthy that after BSA corona formation on the GO surface, the absorption bands at $1728 \mathrm{~cm}^{-1}$ (carboxylic acid) and $\sim 1060 \mathrm{~cm}^{-1}$ (primary alcohol) considerably reduced, suggesting the reduction of $\mathrm{COOH}$ in the GO lattice [6,49]. Nevertheless, the appearance of characteristic absorption bands (1535 and $\left.1650 \mathrm{~cm}^{-1}\right) \mathrm{of}^{-}$ BSA in the FTIR spectrum of BSA@GO indicate the formation of an albumin corona-graphene oxide complex (Figure 2C). 

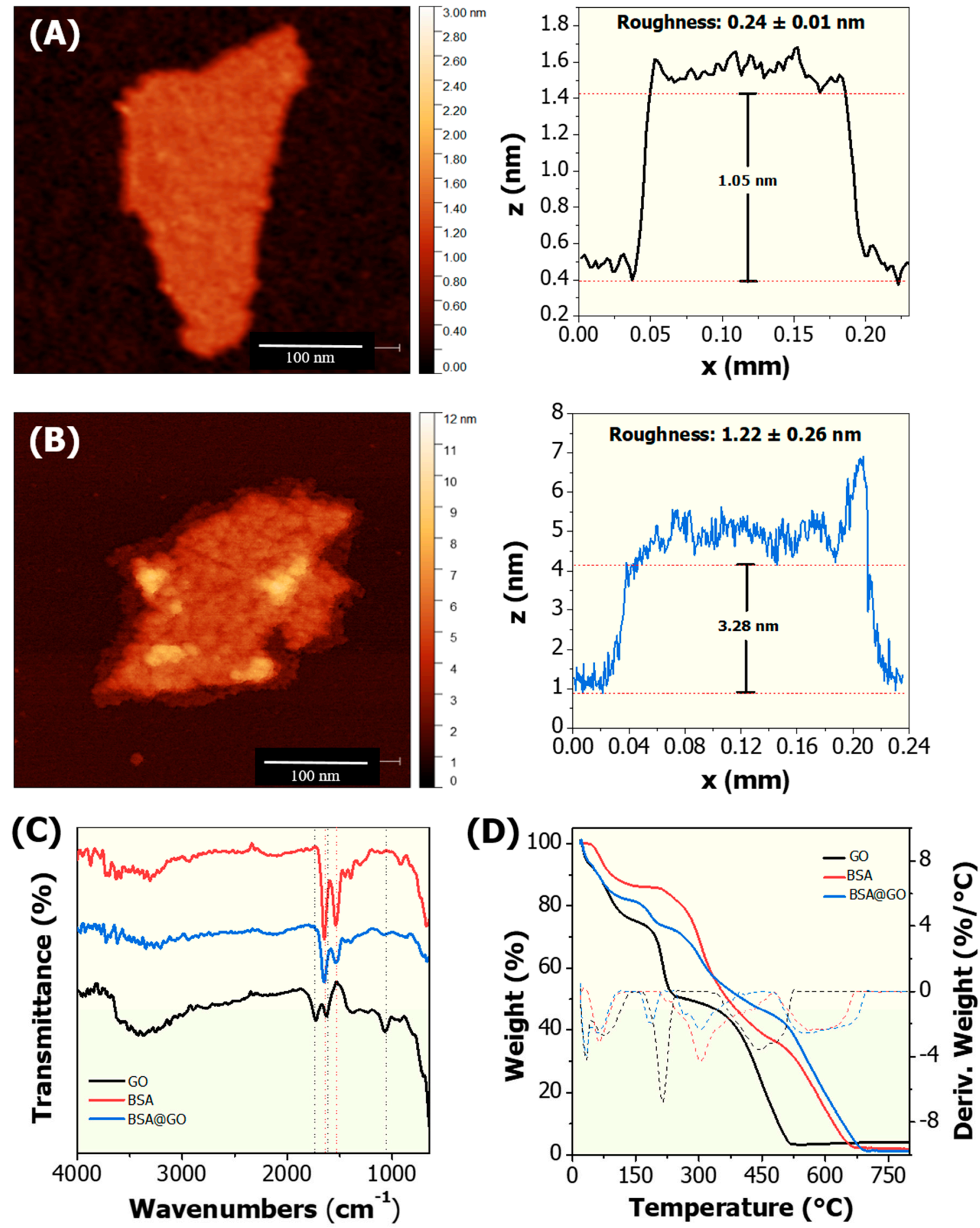

Figure 2. Characterisation of graphene oxide (GO) and the albumin corona coated graphene oxide (BSA@GO) materials: Atomic force microscopy (AFM) images and surface roughness analysis of (A) bare GO and (B) corona coated BSA@GO; (C) Attenuated total reflection Fourier infrared spectroscopy (ATR-FTIR); and (D) Thermogravimetric analysis (TGA) spectra of GO, BSA and BSA@GO.

To further explore the interaction of BSA with the GO surface, thermogravimetric analysis (TGA) was used. The TGA curve (Figure 2D) of GO shows a mass loss of $\sim 16 \%$ until $100^{\circ} \mathrm{C}$, which corresponds to the evaporation of adsorbed water molecules from the surface of GO. The thermal decomposition event observed in the range of $150-300{ }^{\circ} \mathrm{C}$ was attributed to the combustion of labile functional groups such as hydroxyl, carboxyl, epoxy, and then stable carbonyl groups with total weight loss of $\sim 36 \%$. 
This result was confirmed from the DTG curve, which shows a strong exothermic peak at $215{ }^{\circ} \mathrm{C}$, suggesting the burning of these functional groups. It is noteworthy that the thermal decomposition of the main lattice of GO occurred in the temperature range $300-520^{\circ} \mathrm{C}$ with weight loss of $\sim 44 \%$, which was validated from the broad exothermic peak observed in the DTG curve at $440{ }^{\circ} \mathrm{C}$. This data indicate the existence of smaller nanoflakes of $\mathrm{GO}$ with high order of oxidation $(\mathrm{OH}, \mathrm{COOH}, \mathrm{C}=\mathrm{O}, \mathrm{C}-\mathrm{O}-\mathrm{C}$ functional groups). Interestingly, the TGA/DTG curves of GO@BSA display a total weight loss of $12 \%$ in the first exothermic thermal decomposition event $\left(150-300{ }^{\circ} \mathrm{C}\right)$, which is $24 \%$ less than that of GO, suggesting reduction of the labile functional groups (e.g., $\mathrm{COOH}$ ) in the $\mathrm{GO}$ lattice $[6,49]$. In addition, the last exothermic combustion event of the graphene oxide-BSA complex was extended to $705^{\circ} \mathrm{C}$ with total weight loss of $70 \%$, constituted of approximately $26 \% \mathrm{GO}$, indicating the formation of the albumin corona-graphene oxide complex.

Nanomaterial dispersion stability has an important influence on nanotoxicity. In general, nanomaterial surfaces have high free energy; therefore, thermodynamic driving forces act to minimize the surface energy, and consequently, nanomaterials will suffer physical and chemical transformations, such as dissolution, agglomeration, and surface chemistry modifications, upon interaction with biological and environmental media. All these transformations are dependent on medium composition and exposure conditions, including solution $\mathrm{pH}$, ionic strength and composition [22,50]. The synthetized GO shows a high dispersion stability in ultrapure water up to $72 \mathrm{~h}$, monitored by UV-VIS and DLS measurements (Figure S2, supplementary information). However, after the incubation in reconstituted water (Daphnia culture medium) agglomeration and sedimentation behaviours are observed over the incubation time (Figure 3).

(A)

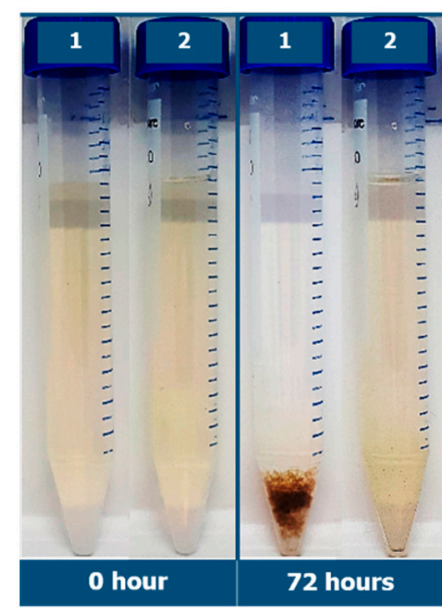

(1) GO (2) BSA@GO
(B)

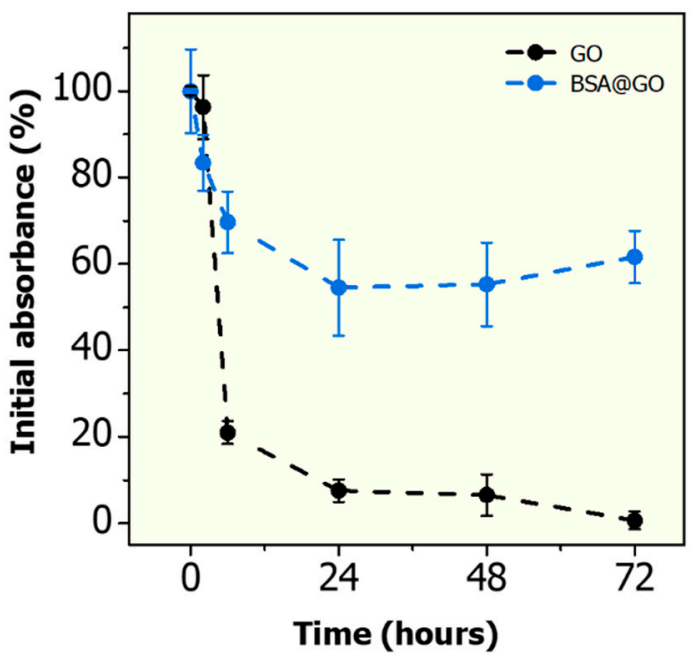

Figure 3. Dispersion stability of GO and BSA@GO materials $\left(10 \mathrm{mg} \mathrm{L}^{-1}\right)$ in reconstituted water from 0 to $72 \mathrm{~h}$ at $20^{\circ} \mathrm{C}$ : (A) Digital picture for visual inspection; and (B) Percentage of material in suspension relative to initial absorbance (at $400 \mathrm{~nm}$ ).

The reconstituted water contains dissolved divalent cation species (i.e., $\mathrm{Mg}^{2+}$ and $\mathrm{Ca}^{2+}$ ), promoting the agglomeration behaviour observed. The presence of these cations can decrease the repulsive energy or increase the attractive energy between the GO particles, resulting in agglomeration phenomena [51]. Interesting, the BSA@GO shows better dispersion stability in reconstituted water and it was observed that approximately $60 \%$ of this hybrid material is stable in the dispersion up to $72 \mathrm{~h}$ (Figure 3 ). The increase in dispersion stability of graphene after albumin corona formation can be explained by the strong steric repulsion forces promoted by BSA adsorption to the GO surface, that prevent the double layer compression effect caused by the cations dissolved in reconstituted water. The hydrodynamic diameter (HD) and zeta potential (ZP) of GO and BSA@GO were evaluated in ultrapure water and reconstituted water (Table 1$)$. 
Table 1. Hydrodynamic diameter (HD), polydispersity index (PdI), and zeta potential (ZP) measurements of GO and BSA@GO dispersions $\left(10 \mathrm{mg} \mathrm{L}^{-1}\right)$ in ultrapure water and reconstituted water at $20^{\circ} \mathrm{C}$.

\begin{tabular}{ccccccc}
\hline \multirow{2}{*}{ Materials } & \multicolumn{3}{c}{ Ultrapure Water } & \multicolumn{3}{c}{ Reconstituted Water } \\
\cline { 2 - 7 } & HD $(\mathbf{n m})$ & PdI & ZP $(\mathbf{m V})$ & HD $(\mathbf{n m})$ & PdI & ZP $(\mathbf{m V})$ \\
\hline GO & $196.7 \pm 2.8$ & $0.232 \pm 0.007$ & $-31.9 \pm 5.9$ & $1490.3 \pm 117.5$ & $0.615 \pm 0.060$ & $-16.3 \pm 0.6$ \\
BSA@GO & $975.8 \pm 123.1$ & $0.834 \pm 0.100$ & $-35.8 \pm 1.7$ & $1715.0 \pm 56.5$ & $0.798 \pm 0.031$ & $-19.3 \pm 1.2$ \\
\hline
\end{tabular}

As expected, an increase in the HD value of GO was observed after the protein corona formation (from $196.7 \mathrm{~nm}$ to $975.8 \mathrm{~nm}$ ) in ultrapure water, and the HD values observed in reconstituted water for GO and BSA@GO are $1490.3 \mathrm{~nm}$ and $1715.0 \mathrm{~nm}$, respectively (Table 1). The protein corona can change the HD values by increasing the particle size, due to the protein coating thickness and/or by leading to particle agglomeration through protein-protein interactions. Although the HD does not represent the real size of non-spherical particles like GO, and DLS analyses performed are not able to distinguish aggregation (strong chemical bonds) from agglomeration (van der Waals bonds) events, it does provide an interesting approach to qualitatively assess the changes in GO after corona formation [48]. In general, $\mathrm{ZP}$ values of $\pm 30 \mathrm{mV}$ indicate that nanoparticles can produce electrostatically stable colloidal dispersions [52]. The GO and BSA@GO show a ZP values of $-35 \pm 1.7 \mathrm{mV}$ in ultrapure water; however, a decrease in this value was observed for GO $(-16.3 \pm 0.6 \mathrm{mV})$ and BSA@GO $(-19.3 \pm 1.2 \mathrm{mV})$ in reconstituted water. Although the $\mathrm{ZP}$ is lower than $\pm 30 \mathrm{mV}$, the albumin corona enhanced the steric stability of GO in reconstituted water (as demonstrated in Figure 3), as a result of the layer of BSA molecules preventing the GO molecules from coming into contact with one another. These results indicate that the BSA@GO material becomes more hydrophilic and could form more hydrogen bonds with $\mathrm{H}_{2} \mathrm{O}$ molecules compared to the $\mathrm{GO}$ materials.

Non-covalent interactions between proteins and GO have a critical influence on the nanomaterial dispersion stability in aqueous medium and lead to the coronation [53]. In addition, GO can absorb biomolecules by different mechanisms such as hydrogen bonding, hydrophobic interaction, $\pi-\pi$ stacking, electrostatic and van der Waals interactions [9,54]. Sun et al. (2018) demonstrated that BSA affects the GO colloidal stability in a nonlinear relationship with the BSA concentration, suggesting an integrated result of compressing electric double layers and steric repulsion induced by the interactions of BSA and GO [9]. More recently, it was also demonstrated that GO materials displaying different lateral sizes and functional groups exhibited different interactions with BSA in aqueous medium. In this case, the water parameters such as ionic strength, solution $\mathrm{pH}$, protein structure and concentration, had a pivotal influence on these nano-bio interactions [13]. Liu et al. (2019) studied the protein corona formation of $\mathrm{GO}$ in aqueous medium containing divalent cations (i.e., $\mathrm{Ca}^{2+}$ and $\mathrm{Mg}^{2+}$ ), concluding that an increase in ionic strength under neutral $\mathrm{pH}$ conditions resulted in stronger binding between human serum albumin (HSA) and GO, as well as a more compact HSA protein layer (corona) on the GO, indicating an important role of electrostatic interactions in controlling HSA-GO complexes [11].

Understanding the interaction of $\mathrm{GO}$ with cadmium is very important for mixture (nano)ecotoxicology as well as to the applications of these materials in water remediation technologies. Herein, the adsorption profiles during equilibrium binding of $\mathrm{Cd}^{2+}$ onto GO and BSA@GO are shown in Figure 4. The adsorption capacity of GO and BSA@GO increased with increasing $\mathrm{Cd}^{2+}$ concentration, the average $\mathrm{Cd}^{2+}$ adsorption values observed are $12 \%$ and $54 \%$ for the GO and BSA@GO, respectively (Table S1). These results confirm that the albumin corona coated graphene oxide adsorbs approximately 4.5 times more cadmium ions from the dissolved phase (reconstituted water) than bare GO. The classical Freundlich model was applied to describe the adsorption equilibrium results obtained (Figure 4). The Freundlich model considers a nonideal multilayer adsorption onto heterogeneous surfaces and its exponential equation is presented by the plot $\log Q_{\mathrm{e}}$ versus $\log \mathrm{C}_{\mathrm{e}}$. 
(A)

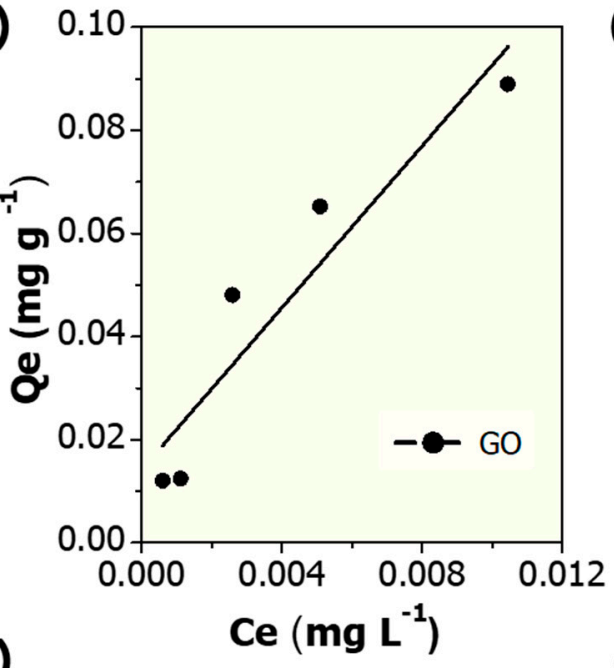

(C)

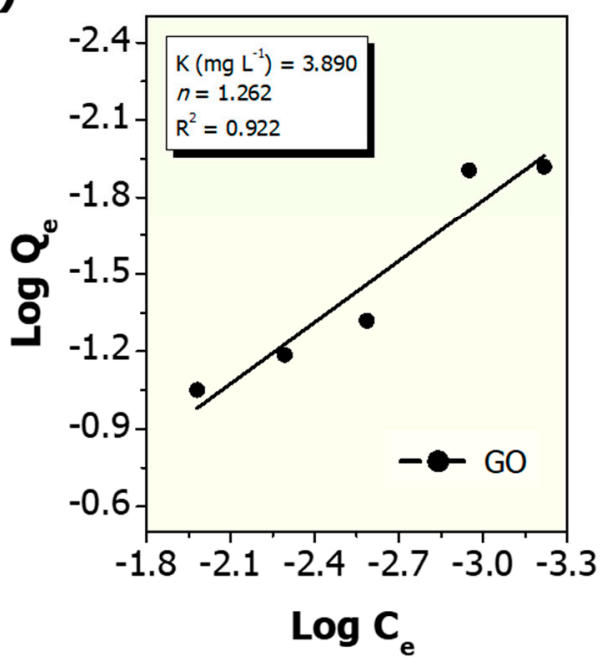

(B)

(D)
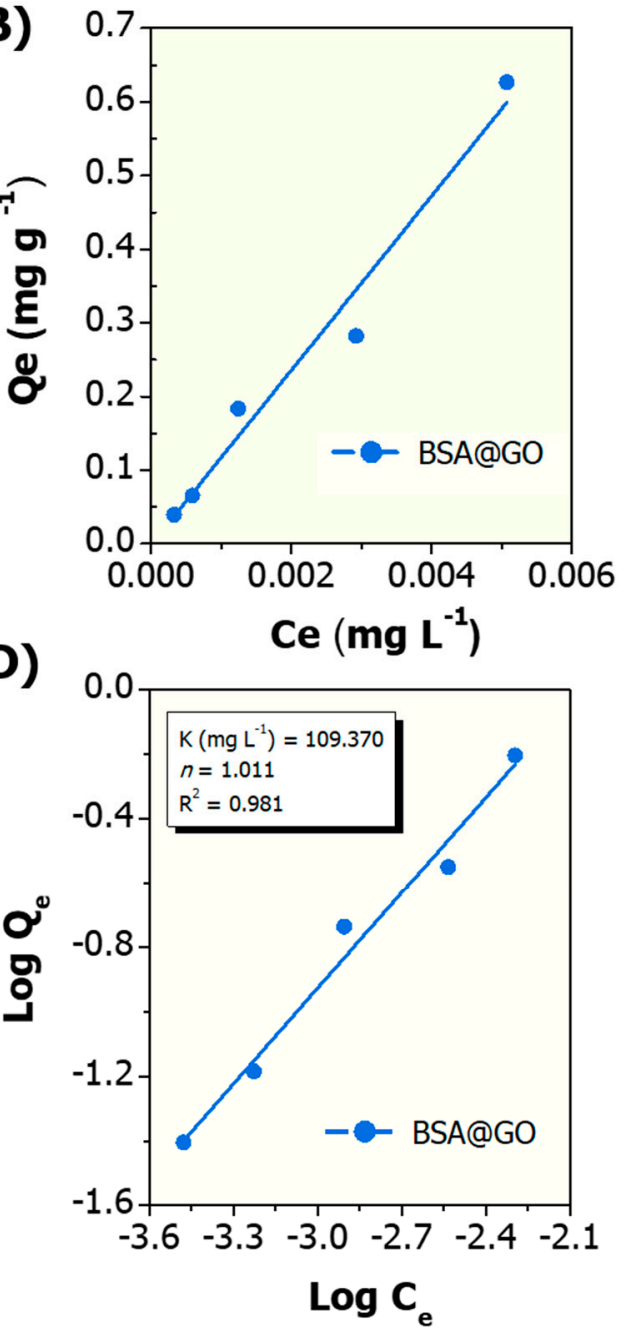

Figure 4. Adsorption capacity of $\mathrm{Cd}^{2+}$ onto the graphene-based materials in reconstituted water at $20^{\circ} \mathrm{C}$. Adsorption isotherms: (A) GO and (B) BSA@GO materials; Freundlich isotherms: (C) GO and (D) BSA@GO materials.

The adsorption behaviour observed by Bian et al. (2015) and $\mathrm{Ni}$ and $\mathrm{Li}$ (2018) for $\mathrm{Cd}^{2+}$ onto graphene oxide is also in agreement with the Freundlich model [31,55]. In our study, the Freundlich parameter $n$ observed for the interaction of $\mathrm{Cd}^{2+}$ with $\mathrm{GO}$ is 1.262 , indicating that the adsorption is favourable under the studied conditions because $n>1.0$ (Figure 4C). On the interaction between $\mathrm{Cd}^{2+}$ and BSA@GO, the $n$ value calculated is 1.011, suggesting that the adsorption is linear because $n \sim 1.0$, that is, the energies are identical for all adsorption sites (Figure 4D). The regression coefficient $\left(R^{2}>0.9\right)$ shows that the experimental data are well fitted by the Freundlich model. It is well-known that the oxygen-containing functional groups (e.g., $-\mathrm{OH},-\mathrm{COOH}$ ) on the $\mathrm{GO}$ surface play an important role in the adsorption of $\mathrm{Cd}^{2+}$, probably by cation exchange and electrostatic attraction between the ions and the functional groups [55]. The superior $\mathrm{Cd}^{2+}$ adsorption capacity of BSA@GO compared to bare GO could be due to the enhanced number of active sites/oxygen-containing functional groups that can interact with $\mathrm{Cd}^{2+}$ through ion exchange, surface complexation and chelation [56]. Further, the higher material surface roughness of BSA@GO as observed in the AFM image (Figure 2B) could enhance the contact area of interaction. Another advantage of BSA@GO is its improved dispersion stability in reconstituted water (Figure 3). Likewise, computational molecular modelling and experimental data showed that $\mathrm{Cd}^{2+}$ mainly interacts with the negatively charged amino acid residues of serum albumin (i.e., Asp451, Pro447 and Gln221) predominately through electrostatic forces [57]. Overall, the albumin 
corona reduces therefore the material agglomeration behaviour and generates more free functional groups/sites for $\mathrm{Cd}^{2+}$ interaction when compared to bare GO [58].

Assessing the nanoecotoxicological effects of GO is a key step towards a proactive and responsible innovation and governance of new materials, ensuring that their risks to environmental health are considered in parallel to development of applications. Once released into the aquatic environment, the GO would interact and co-exist with other pre-existing environmental contaminants; therefore, it is necessary to understand the impacts of combined toxicity with co-pollutants on aquatic model organisms. Nanomaterials could mitigate the toxicity of co-contaminants by adsorbing the pollutant and reducing its free concentration (and bioavailability), but if the pollutant-adsorbed nanomaterials are taken up by the organisms and the co-pollutant dissociates from the nanomaterial surface the toxicity could be enhanced $[26,27,59]$. Therefore, first, we evaluated the acute toxicity of bare GO and BSA@GO materials to D. magna. And after $72 \mathrm{~h}$ of exposure acute toxicological effects (immobilisation) were completely absent for both materials up to $100 \mathrm{mg} \mathrm{L}^{-1}$, which is considered the highest-dose recommended for ecotoxicity testing of chemicals according to OECD guidelines (Table S2, supplementary information). Moreover, it should be noted that the ecotoxicity of graphene-based materials against aquatic organisms is a complex issue due to significant challenges in dispersion and dosing and the aforementioned transformations [60]. For example, Lv et al. (2018) [61] demonstrated that graphene oxide is toxic to $D$. magna $\left(72 \mathrm{~h}-\mathrm{LC}_{50}=45.4 \mathrm{mg} \mathrm{L}^{-1}\right)$ while another study reported a $72 \mathrm{~h}-\mathrm{LC}_{50}$ value of $145 \mathrm{mg} \mathrm{L}^{-1}$ [31]. In part, the variability in the results published so far is associated with differences in the graphene physico-chemical properties (e.g., flake size, structural defects, oxygenated groups and purity) and the agglomeration/aggregation events occurring in the exposure medium [62,63]. Additionally, surface chemistry modifications such as interactions with natural organic matter (NOM) can modulate the toxicity of GO-based materials towards D. magna $[64,65]$. The lack of any effects from our GO and BSA@GO materials over $72 \mathrm{~h}$ is related to the fact that we used environmentally relevant concentrations, rather than dosing until effects were observed.

The hazard of cadmium in aquatic systems is a well-known environmental health concern due to its non-biodegradability, bioaccumulation, and toxic effects to aquatic organisms such as plants, invertebrates and fish [66]. Besides, this heavy metal has been considered a model pollutant for ecotoxicology and water quality research [67]. Furthermore, it has been demonstrated that $\mathrm{Cd}^{2+}$ can promote severe toxic effects in D. magna by inducing oxidative stress (production of reactive oxygen species, ROS) and genotoxicity (DNA damage), as well as long-term negative effects on the reproduction and metabolism of daphnids [68]. In our study, the $\mathrm{EC}_{50}$ values observed are 0.36 , 0.18 and $0.12 \mathrm{mg} \mathrm{L}^{-1}$ after exposure of D. magna neonates to $\mathrm{Cd}^{2+}$ for 24,48 and $72 \mathrm{~h}$, respectively (Figure 5), which is consistent with results reported by Qu et al. (2013) [69].

An important control for this work was to assess whether BSA-only impacts on the toxicity of $\mathrm{Cd}^{2+}$ to D. magna. We verified that BSA at a fixed concentration of $5.0 \mathrm{mg} \mathrm{L}^{-1}$ mitigated the cadmium toxicity (Figure 6). The $\mathrm{EC}_{50}$ values observed for $\mathrm{Cd}^{2+}$ following co-exposure with BSA at $5.0 \mathrm{mg} \mathrm{L}^{-1}$ are $0.44,0.30$ and $0.18 \mathrm{mg} \mathrm{L}^{-1}$ to D. magna for 24,48 and $72 \mathrm{~h}$, respectively (Figure 6). These results indicate that BSA mitigates the acute toxicity of cadmium by approximately $22.2 \%, 66.6 \%$ and $50.0 \%$ at 24,48 , and $72 \mathrm{~h}$, respectively, when compared to the $\mathrm{EC}_{50}$ values of $\mathrm{Cd}^{2+}$-only (Figure 5). Probably, the Cd-absorbed to BSA is less bioavailable to the daphnids, and therefore a reduction in $\mathrm{Cd}^{2+}$ toxicity is observed. So far, the related studies in the literature were mainly focused on investigating the effects of non-protein molecules (i.e., humic and fulvic acids) on the toxicity of cadmium during co-exposure experiments with D. magna [70]. In general, the addition of humic substances during toxicity testing reduces the bioavailability of heavy metals to daphnids, with consequent reduction in the acute toxicity values. Recently, Lin et al. (2018) showed that the addition of different types of peptides and proteins (i.e., tryptone, phycocyanin and BSA) can modulate the toxicity of pyrene (organic pollutant) to D. magna [71]. 


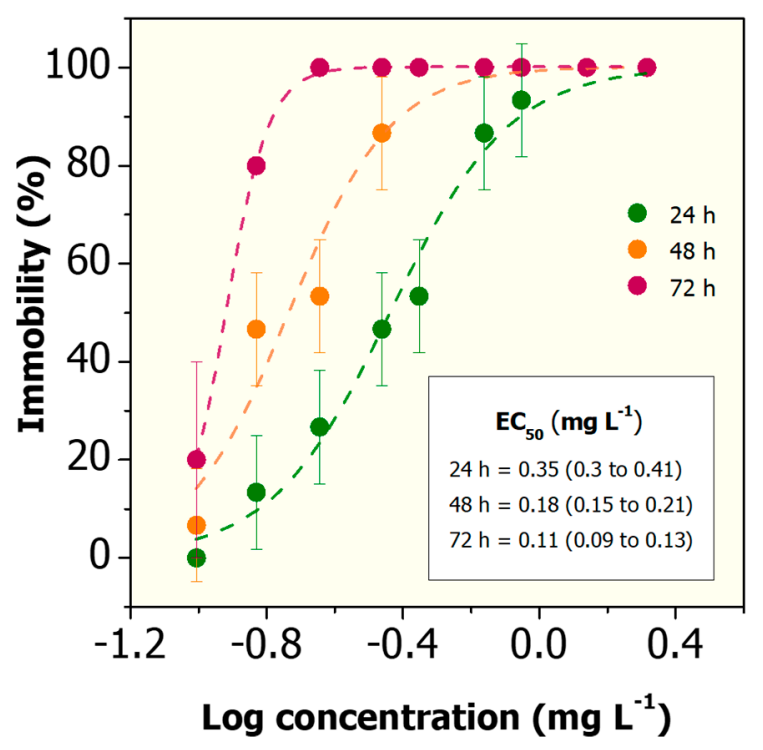

Figure 5. Acute toxicity of $\mathrm{Cd}^{2+}$ on D. magna after 24, 48, and $72 \mathrm{~h}$ of exposure in reconstituted water. PriProbit software was used to obtain the $\mathrm{EC}_{50}$ values via Probit analysis including $95 \%$ confidence limits.

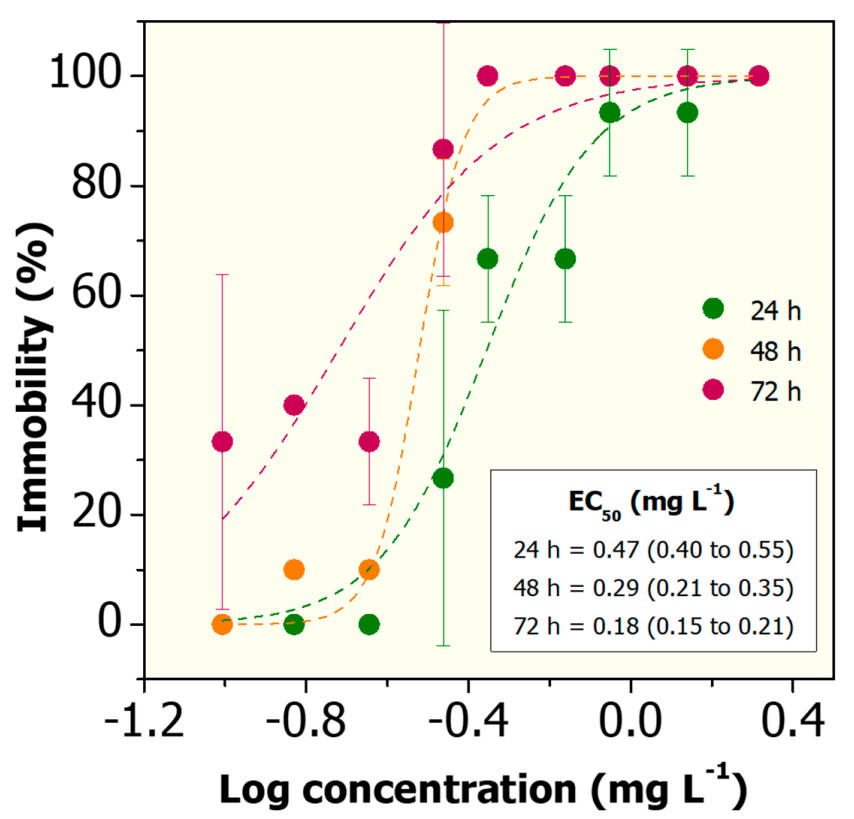

Figure 6. Acute toxicity of $\mathrm{Cd}^{2+}$ following co-exposure with BSA at $5.0 \mathrm{mg} \mathrm{L}^{-1}$ to D. magna after 24, 48 and $72 \mathrm{~h}$ in reconstituted water. PriProbit software was used to obtain the $\mathrm{EC}_{50}$ values via Probit analysis including $95 \%$ confidence limits.

To assess the role of the BSA corona on $\mathrm{Cd}^{2+}$ and GO mixture ecotoxicity, we evaluate the acute toxicity of GO and BSA@GO after co-exposure with $\mathrm{Cd}^{2+}$ to D. magna. As shown in Table 2, the immobilisation of D. magna by $\mathrm{Cd}^{2+}$ decreases following the co-exposure of $\mathrm{Cd}^{2+}$ with both graphene-based materials, indicating that the toxicity of heavy metal is mitigated by binding to the GO materials, with binding to BSA in the corona being especially effective at removing $\mathrm{Cd}^{2+}$ from solution and thus reducing its bioavailability to daphnids. The toxicity values observed after mixing $\mathrm{Cd}^{2+}$ with BSA@GO are lower than those obtained from mixtures with bare GO. 
Table 2. The $\mathrm{EC}_{50}$ values (immobilisation) obtained from exposure to mixtures of $\mathrm{Cd}^{2+}\left(0.1-2.1 \mathrm{mg} \mathrm{L}^{-1}\right)$ at three concentrations $\left(0.1,1.0\right.$ and $\left.10 \mathrm{mg} \mathrm{L}^{-1}\right)$ of GO and BSA@GO in D. magna after 24, 48 and $72 \mathrm{~h}$. PriProbit software was used to obtain the $\mathrm{EC}_{50}$ values via Probit analysis including the $95 \%$ confidence limits.

\begin{tabular}{cccc}
\hline \multirow{2}{*}{ Treatments } & \multicolumn{3}{c}{ EC $_{\mathbf{5 0}}$ ( $\left.\mathbf{m g ~ L}^{\mathbf{- 1}}\right)$} \\
\cline { 2 - 4 } & $\mathbf{2 4} \mathbf{~ h}$ & $\mathbf{4 8 ~} \mathbf{~ h}$ & $\mathbf{7 2 ~} \mathbf{~}$ \\
\hline $\mathrm{Cd}^{2+}$ & $0.35(0.3$ to 0.41$)$ & $0.18(0.15$ to 0.21$)$ & $0.11(0.09$ to 0.13$)$ \\
$\mathrm{Cd}^{2+}+\mathrm{GO}\left(0.1 \mathrm{mg} \mathrm{L}^{-1}\right)$ & $0.64(0.54$ to 0.74$)$ & $0.20(0.17$ to 0.23$)$ & $0.12(0.10$ to 0.14$)$ \\
$\mathrm{Cd}^{2+}+\mathrm{GO}\left(1.0 \mathrm{mg} \mathrm{L}^{-1}\right)$ & $0.79(0.70$ to 0.86$)$ & $0.29(0.20$ to 0.42$)$ & $0.16(0.13$ to 0.19$)$ \\
$\mathrm{Cd}^{2+}+\mathrm{GO}\left(10 \mathrm{mg} \mathrm{L}^{-1}\right)$ & $1.0(0.86$ to 1.17$)$ & $0.48(0.42$ to 0.55$)$ & $0.20(0.17$ to 0.23$)$ \\
$\mathrm{Cd}^{2+}+\mathrm{BSA} @ \mathrm{GO}\left(0.1 \mathrm{mg} \mathrm{L}^{-1}\right)$ & $0.71(0.58$ to 0.87$)$ & $0.30(0.25$ to 0.37$)$ & $0.10(0.08$ to 0.13$)$ \\
$\mathrm{Cd}^{2+}+$ BSA@GO $\left(1.0 \mathrm{mg} \mathrm{L}^{-1}\right)$ & $0.95(0.82$ to 1.10$)$ & $0.61(0.53$ to 0.70$)$ & $0.21(0.18$ to 0.24$)$ \\
$\mathrm{Cd}^{2+}+$ BSA@GO $\left(10 \mathrm{mg} \mathrm{L}^{-1}\right)$ & $1.43(1.26$ to 1.63$)$ & $1.17(1.04$ to 1.33$)$ & $0.76(0.68$ to 0.86$)$ \\
\hline
\end{tabular}

The 48 h-EC 50 values observed following the exposure at a high-dose of GO and BSA@GO $\left(10 \mathrm{mg} \mathrm{L}^{-1}\right)$ with $\mathrm{Cd}^{2+}$ are $0.48 \mathrm{mg} \mathrm{L}^{-1}$ and $1.17 \mathrm{mg} \mathrm{L}^{-1}$, respectively. These data demonstrate that both materials can mitigate the cadmium toxicity, but that the BSA@GO material is more effective than GO and BSA-only. Therefore, the improvement in $\mathrm{Cd}^{2+}$ adsorption capacity to BSA@GO compared to GO could effectively reduce the bioavailability of this metal in solution and consequently alleviate the toxicity. Moreover, exposure to low concentrations of GO and BSA@GO $\left(0.1 \mathrm{mg} \mathrm{L}^{-1}\right)$ with $\mathrm{Cd}^{2+}$ shows no effect on toxicity at $72 \mathrm{~h}$ in comparation with the control system $\left(\mathrm{Cd}^{2+}\right.$ only), suggesting that the exposure time and concentration of adsorbent materials are important parameters to be considered in future comparative studies.

As reported by $\mathrm{Ni}$ and $\mathrm{Li}$ (2018) [31], GO can mitigate the acute toxicity of $\mathrm{Cd}^{2+}$ against D. magna, and the mitigation of the toxicity of heavy metal ions brought about by GO is attributed to the high adsorption and low desorption capacity, leading to decreased bioaccumulation of heavy metal ions in the organism tissue. Besides, it was also reported that GO causes a reduction in biochemical toxicity endpoints such as oxidative stress (ROS) monitored by enzymatic assays, including superoxide dismutase (SOD), malondialdehyde (MDA) and reduced glutathione (GSH), when co-exposed with heavy metals. Similarly, we can therefore conclude that the reduction in $\mathrm{Cd}^{2+}$ toxicity by bare $\mathrm{GO}$ and BSA@GO are also probably due to decreased concentrations of $\mathrm{Cd}^{2+}$-free in the medium and the weak desorption of metal ions from metal-adsorbed graphene materials.

Regarding the environmental relevance of this study, we can speculate about the potential for future applications of BSA@GO hybrid materials for environmental remediation, considering its high $\mathrm{Cd}^{+}$adsorption capacity and ecotoxicity mitigating effect. However, it is well known that nanomaterials could be transferred to other organisms due to ecological trophic interactions; therefore, it is important to study the ecotoxicity of protein corona coated GO materials in mixtures with co-pollutants to other aquatic model organisms and in food chains. For example, it was demonstrated that GO can enhance the toxicity of $\mathrm{Cd}^{2+}$ against Palaemon pandaliformis (shrimp) and Geophagus iporangensis (freshwater fish), disturbing the metabolism (oxygen consumption and ammonia excretion) of these aquatic species [28,72].

The biological and environmental relevance of nanomaterial coronas is a central issue to advance nanobiosciences, nano(eco)toxicology, and nanosafety research in a broad sense [73-75]. In this regard, Nasser and Lynch (2016) [76] showed that protein eco-corona formation should be considered during toxicity assessment of nanomaterials with the D. magna model. The biomolecules secreted by $D$. magna (i.e., proteins and metabolites) in the testing medium impacts on the toxicological profile of nanomaterials [77-79]. These studies have explored the "conditioned medium" approach to demonstrate the impacts of eco-corona formation on nanomaterials uptake and toxicity to D. magna. Basically, the conditioned medium consists of a mixture of proteins and metabolites secreted by daphnids in the medium during a specific interval of incubation time. Herein, we assess differences in 
acute toxicity to $\mathrm{Cd}^{2+}$-only treatment compared to the mixture $\left(\mathrm{Cd}^{2+}+\mathrm{GO}\right)$ against $D$. magna using the conditioned medium test (CMT) when compared to the experiments performed in reconstituted water (Table S3, supplementary information), with little difference observed. It should be noted however that the total protein content secreted by D. magna was very low $\left(0.02 \mu \mathrm{g} \mathrm{mL}^{-1}\right)$ in the conditioned medium tested in this work when compared with the results reported by Nasser and Lynch (2016) [76] that reached approximatively $140 \mu \mathrm{g} \mathrm{mL}^{-1}$ using $\mathrm{HH}$ Combo medium. These results suggest therefore that the absence of effects in our toxicity evaluations exploring the conditioned medium approach could be linked to the low amount of protein in the CMT, which was measured by Bradford assay (Table S4, supplementary information). Indeed, it is well known that the protein content is a critical parameter for nanomaterial corona formation and their biological effects $[5,48,80]$. Thus, our findings highlighted the importance of developing a standard protocol for medium conditioning, medium supplementation with relevant biomolecules or pre-formation of coronas, as well as a need for advanced interlaboratory studies for a better characterisation and understanding of the impacts of the protein and metabolite eco-corona during Daphnia nanotoxicity testing and its implications for nanosafety regulation [81].

\section{Conclusions}

In summary, we demonstrate for the first time that albumin corona formation on GO surfaces impacts on its interactions with $\mathrm{Cd}^{2+}$ during mixture toxicity testing with the model ecotoxicity species D. magna. Our results show positive effects in terms of: (i) improvement in the material dispersion stability over time in reconstituted water; (ii) increased adsorption capacity for $\mathrm{Cd}^{2+}$; and (iii) enhancement of the mitigation effect on $\mathrm{Cd}^{2+}$ acute toxicity to D. magna for BAS@GO compared to GO. These findings suggest that exploring protein corona formation on GO is an interesting approach to produce hybrid nanomaterials for adsorption of heavy metals and mitigation of heavy metal ecotoxicity. It is, however, important to note that these were acute studies $(72 \mathrm{~h})$ and thus longer-term studies, as well as investigation of the impacts of the graphene corona in other aquatic model organisms including more complex environmental exposure systems. Finally, all data from this study are available for re-use via the NanoCommons Knowledge Base and are fully curated using ontologically validated methodologies to advance safe-by-design approaches connecting graphene-based materials, mixture ecotoxicity assessment and remediation of heavy metals from water.

Supplementary Materials: The following are available online at http://www.mdpi.com/2079-4991/10/10/1936/s1, Figure S1: Characterisation of GO by AFM, Raman, XRD, UV-VIS and XPS; Figure S2: Dispersion stability of GO over time monitored by UV-VIS and DLS; Table S1: Percentage of $\mathrm{Cd}^{2+}$ adsorption on GO and BSA@GO materials by ICP-MS; Table S2: Acute toxicity of GO and BSA@GO on D. magna in reconstituted water; Table S3: Acute toxicity of $\mathrm{Cd}^{2+}, \mathrm{GO}$ and co-exposure $\mathrm{GO}+\mathrm{Cd}^{2+}$ on D. magna in conditioned medium (CMT) and Table S4: Total protein quantification in conditioned medium (CMT) by Bradford assay.

Author Contributions: Conceptualization, D.S.T.M. and I.L.; methodology, D.S.T.M.; G.H.D.S.; and A.M.d.Z.M. software, A.G.P. and I.L.; validation, D.S.T.M., A.G.P. and I.L.; data curation, A.G.P.; writing一original draft preparation, D.S.T.M.; G.H.D.S.; L.U.K.; A.M.Z.D.M.; A.G.P.; I.L.; writing—review and editing, D.S.T.M. and I.L.; supervision, D.S.T.M. and I.L.; project administration D.S.T.M. and I.L.; funding acquisition, D.S.T.M. and I.L. All authors have read and agreed to the published version of the manuscript.

Funding: FAPESP-UoB research grant (Project. No. 19/07058-0), Horizon 2020 NanoCommons project (Grant Agreement No. 731032), FAPESP BPE Fellowship (Project No. 18/25140-3) and CNPq PQ-2 Fellowship (Project No. 313494/2017-7).

Acknowledgments: D.S.T.M. thanks the Sao Paulo Research Foundation (FAPESP) for the visiting research fellowship at GEES/UoB and the National Council for Scientific and Technological Development (CNPq) for the productivity research fellowship. I.L., D.S.T.M. and A.G.P. thank the Horizon 2020 NanoCommons project. L.U.K. and A.M.Z.D.M. extend gratitude to the Birmingham-Brazil Visiting Fellows scheme and CAPES-USP PrInt program for the scholarships, respectively. The authors are grateful to LNNano/CNPEM facilities (AFM, XPS, XRD, Raman and Daphnia), UoB facilities (DLS/ELS, TGA and ICP-MS), the National Institute for Complex Functional Materials (INCT-Inomat), the National System of Laboratories on Nanotechnologies (SisNANO/MCTI), and the FAPESP-UoB research grant.

Conflicts of Interest: The authors declare no conflict of interest. 


\section{References}

1. Fadeel, B.; Bussy, C.; Merino, S.; Vázquez, E.; Flahaut, E.; Mouchet, F.; Evariste, L.; Gauthier, L.; Koivisto, A.J.; Vogel, U.B.; et al. Safety assessment of graphene-based materials: Focus on human health and the environment. ACS Nano 2018, 12, 10582-10620. [CrossRef] [PubMed]

2. Paula, A.J.; Silveira, C.P.; Martinez, D.S.T.; Filho, A.G.S.; Romero, F.V.; Fonseca, L.C.; Tasic, L.; Alves, O.L.; Durán, N. Topography-driven bionano-interactions on colloidal silica nanoparticles. ACS Appl. Mater. Interfaces 2014, 6, 3437-3447. [CrossRef]

3. Durán, N.; Silveira, C.P.; Durán, M.; Martinez, D.S.T. Silver nanoparticle protein corona and toxicity: A mini-review. J. Nanobiotechnol. 2015, 13, 55. [CrossRef] [PubMed]

4. Fonseca, L.C.; De Araújo, M.M.; De Moraes, A.C.M.; Da Silva, D.S.; Ferreira, A.G.; Franqui, L.S.; Martinez, D.S.T.; Alves, O.L. Nanocomposites based on graphene oxide and mesoporous silica nanoparticles: Preparation, characterization and nanobiointeractions with red blood cells and human plasma proteins. Appl. Surf. Sci. 2018, 437, 110-121. [CrossRef]

5. Chetwynd, A.J.; Wheeler, K.E.; Lynch, I. Best practice in reporting corona studies: Minimum Information about Nanomaterial Biocorona Experiments (MINBE). Nano Today 2019, 28, 100758. [CrossRef] [PubMed]

6. Liu, J.; Fu, S.; Yuan, B.; Li, Y.; Deng, Z. Toward a universal "adhesive nanosheet" for the assembly of multiple nanoparticles based on a protein-induced reduction/decoration of graphene oxide. J. Am. Chem. Soc. 2010, 132, 7279-7281. [CrossRef]

7. Yang, P.; Liu, Q.; Liu, J.; Zhang, H.; Li, Z.; Li, R.; Liu, L.; Wang, J. Bovine serum albumin-coated graphene oxide for effective adsorption of uranium(VI) from aqueous solutions. Ind. Eng. Chem. Res. 2017, 56, 3588-3598. [CrossRef]

8. Yu, X.; Sun, S.; Zhou, L.; Miao, Z.; Zhang, X.; Su, Z.; Wei, G. Removing metal ions from water with graphene-bovine serum albumin hybrid membrane. Nanomaterials 2019, 9, 276. [CrossRef]

9. Sun, B.; Zhang, Y.; Chen, W.; Wang, K.; Zhu, L. Concentration dependent effects of bovine serum albumin on graphene oxide colloidal stability in aquatic environment. Environ. Sci. Technol. 2018, 52, 7212-7219. [CrossRef]

10. Shakiba, S.; Hakimian, A.; Barco, L.R.; Louie, S.M. Dynamic intermolecular interactions control adsorption from mixtures of natural organic matter and protein onto titanium dioxide nanoparticles. Environ. Sci. Technol. 2018, 52, 14158-14168. [CrossRef]

11. Liu, X.; Yan, C.; Chen, K.L. Adsorption of human serum albumin on graphene oxide: Implications for protein corona formation and conformation. Environ. Sci. Technol. 2018, 53, 8631-8639. [CrossRef] [PubMed]

12. Yan, C.; Cheng, T.; Shang, J. Effect of bovine serum albumin on stability and transport of kaolinite colloid. Water Res. 2019, 155, 204-213. [CrossRef] [PubMed]

13. Sun, B.; Zhang, Y.; Liu, Q.; Yan, C.; Xiao, B.; Yang, J.; Liu, M.; Zhu, L. Lateral size dependent colloidal stability of graphene oxide in water: Impacts of protein properties and water chemistry. Environ. Sci. Nano 2020, 7, 634-644. [CrossRef]

14. Deng, R.; Lin, D.; Zhu, L.; Majumdar, S.; White, J.C.; Gardea-Torresdey, J.L.; Xing, B. Nanoparticle interactions with co-existing contaminants: Joint toxicity, bioaccumulation and risk. Nanotoxicology 2017, 11, 591-612. [CrossRef] [PubMed]

15. Robinson, R.L.M.; Lynch, I.; Peijnenburg, W.J.G.M.; Rumble, J.; Klaessig, F.; Marquardt, C.; Rauscher, H.; Puzyn, T.; Purian, R.; Åberg, C.; et al. How should the completeness and quality of curated nanomaterial data be evaluated? Nanoscale 2016, 8, 9919-9943. [CrossRef]

16. Barnard, A.S.; Motevalli, B.; Parker, A.J.; Fischer, J.M.; Feigl, C.A.; Opletal, G.; Fischer, M. Nanoinformatics, and the big challenges for the science of small things. Nanoscale 2019, 11, 19190-19201. [CrossRef]

17. Brown, K.A.; Brittman, S.; Maccaferri, N.; Jariwala, D.; Celano, U. Machine learning in nanoscience: Big data at small scales. Nano Lett. 2019, 20, 2-10. [CrossRef]

18. Afantitis, A.; Melagraki, G.; Isigonis, P.; Tsoumanis, A.; Varsou, D.D.; Valsami-Jones, E.; Papadiamantis, A.; Ellis, L.-J.A.; Sarimveis, H.; Doganis, P.; et al. NanoSolveIT Project: Driving nanoinformatics research to develop innovative and integrated tools for in silico nanosafety assessment. Comput. Struct. Biotechnol. J. 2020, 18, 583-602. [CrossRef]

19. Labouta, H.I.; Asgarian, N.; Rinker, K.D.; Cramb, D.T. Meta-analysis of nanoparticle cytotoxicity via data-mining the literature. ACS Nano 2019, 13, 1583-1594. [CrossRef] 
20. Oh, E.; Liu, R.; Nel, A.; Gemill, K.B.; Bilal, M.; Cohen, Y.; Medintz, I.L. Meta-analysis of cellular toxicity for cadmium-containing quantum dots. Nat. Nanotechnol. 2016, 11, 479-486. [CrossRef]

21. Bilal, M.; Oh, E.; Liu, R.; Breger, J.C.; Medintz, I.L.; Cohen, Y. Bayesian network resource for meta-analysis: Cellular toxicity of quantum dots. Small 2019, 15, e1900510. [CrossRef] [PubMed]

22. Geitner, N.K.; Hendren, C.O.; Cornelis, G.; Kaegi, R.; Lead, J.R.; Lowry, G.V.; Lynch, I.; Nowack, B.; Petersen, E.J.; Bernhardt, E.; et al. Harmonizing across environmental nanomaterial testing media for increased comparability of nanomaterial datasets. Environ. Sci. Nano 2020, 7, 13-36. [CrossRef]

23. Wilkinson, M.D.; Dumontier, M.; Aalbersberg, I.J.; Appleton, G.; Axton, J.M.; Baak, A.; Blomberg, N.; Boiten, J.-W.; Santos, L.O.B.D.S.; Bourne, P.E.; et al. The FAIR Guiding Principles for scientific data management and stewardship. Sci. Data 2016, 3, 160018. [CrossRef] [PubMed]

24. Kortenkamp, A.; Faust, M. Regulate to reduce chemical mixture risk. Science 2018, 361, 224-226. [CrossRef] [PubMed]

25. Escher, B.I.; Stapleton, H.M.; Schymanski, E.L. Tracking complex mixtures of chemicals in our changing environment. Science 2020, 367, 388-392. [CrossRef]

26. Liu, Y.; Nie, Y.; Wang, J.; Wang, J.; Wang, X.; Chen, S.; Zhao, G.; Wu, L.; Xu, A. Mechanisms involved in the impact of engineered nanomaterials on the joint toxicity with environmental pollutants. Ecotoxicol. Environ. Saf. 2018, 162, 92-102. [CrossRef]

27. Naasz, S.; Altenburger, R.; Kühnel, D. Environmental mixtures of nanomaterials and chemicals: The Trojan-horse phenomenon and its relevance for ecotoxicity. Sci. Total. Environ. 2018, 635, 1170-1181. [CrossRef]

28. De Medeiros, A.M.Z.; Côa, F.; Alves, O.L.; Martinez, D.S.T.; Barbieri, E. Metabolic effects in the freshwater fish Geophagus iporangensis in response to single and combined exposure to graphene oxide and trace elements. Chemosphere 2020, 243, 125316. [CrossRef]

29. Kim, K.T.; Klaine, S.J.; Lin, S.; Ke, P.C.; Kim, S.D. Acute toxicity of a mixture of copper and single-walled carbon nanotubes toDaphnia magna. Environ. Toxicol. Chem. 2010, 29, 122-126. [CrossRef]

30. Revel, M.; Fournier, M.; Robidoux, P.Y. Toxic effect of single walled carbon nanotubes combined with cadmium to the crustacean daphnia magna. Int. Lett. Nat. Sci. 2015, 42, 50-61. [CrossRef]

31. Ni, L.; Li, Y. Role of graphene oxide in mitigated toxicity of heavy metal ions on Daphnia magna. RSC Adv. 2018, 8, 41358-41367. [CrossRef]

32. Liu, Y.; Fan, W.; Xu, Z.; Peng, W.; Luo, S. Comparative effects of graphene and graphene oxide on copper toxicity to Daphnia magna: Role of surface oxygenic functional groups. Environ. Pollut. 2018, 236, 962-970. [CrossRef] [PubMed]

33. Nasser, F.; Lynch, I. Updating traditional regulatory tests for use with novel materials: Nanomaterial toxicity testing with Daphnia magna. Saf. Sci. 2019, 118, 497-504. [CrossRef]

34. Ellis, L.-J.A.; Valsami-Jones, E.; Lynch, I. Exposure medium and particle ageing moderate the toxicological effects of nanomaterials to Daphnia magna over multiple generations: A case for standard test review? Environ. Sci. Nano 2020, 7, 1136-1149. [CrossRef]

35. Lucidchart. Online Diagram Software and Visual Solution. Available online: https://www.lucidchart.com/ pages/ (accessed on 15 May 2020).

36. SciNote. Free Electronic Lab Notebook (ELN). Available online: https://www.scinote.net/ (accessed on 15 May 2020).

37. Hastings, J.; Jeliazkova, N.; Owen, G.; Tsiliki, G.; Munteanu, C.R.; Steinbeck, C.; Willighagen, E. eNanoMapper: Harnessing ontologies to enable data integration for nanomaterial risk assessment. J. Biomed. Semant. 2015, 6, 10. [CrossRef]

38. Hummers, W.S.; Offeman, R.E. Preparation of graphitic oxide. J. Am. Chem. Soc. 1958, 80, 1339. [CrossRef]

39. Sakuma, M. Probit analysis of preference data. Appl. Entomol. Zool. 1998, 33, 339-347. [CrossRef]

40. Robinson, R.L.M.; Cronin, M.T.D.; Richarz, A.-N.; Rallo, R. An ISA-TAB-Nano based data collection framework to support data-driven modelling of nanotoxicology. Beilstein J. Nanotechnol. 2015, 6, 1978-1999. [CrossRef]

41. Sun, B.; Fernandez, M.; Barnard, A.S. Statistics, damned statistics and nanoscience-Using data science to meet the challenge of nanomaterial complexity. Nanoscale Horiz. 2016, 1, 89-95. [CrossRef]

42. Izak-Nau, E.; Huk, A.; Reidy, B.; Uggerud, H.; Vadset, M.; Eiden, S.; Voetz, M.; Himly, M.; Duschl, A.; Dusinska, M.; et al. Impact of storage conditions and storage time on silver nanoparticles' physicochemical properties and implications for their biological effects. RSC Adv. 2015, 5, 84172-84185. [CrossRef] 
43. Mitrano, D.M.; Motellier, S.; Clavaguera, S.; Nowack, B. Review of nanomaterial aging and transformations through the life cycle of nano-enhanced products. Environ. Int. 2015, 77, 132-147. [CrossRef] [PubMed]

44. Pan, S.; Aksay, I.A. Factors controlling the size of graphene oxide sheets produced via the graphite oxide route. ACS Nano 2011, 5, 4073-4083. [CrossRef] [PubMed]

45. De Sousa, M.; Martins, C.H.Z.; Franqui, L.S.; Fonseca, L.C.; Delite, F.S.; Lanzoni, E.M.; Martinez, D.S.T.; Alves, O.L. Covalent functionalization of graphene oxide with d-mannose: Evaluating the hemolytic effect and protein corona formation. J. Mater. Chem. B 2018, 6, 2803-2812. [CrossRef] [PubMed]

46. Clemente, Z.; Silva, G.H.; Nunes, M.C.D.S.; Martinez, D.S.T.; Maurer-Morelli, C.V.; Thomaz, A.A.; Castro, V.L. Exploring the mechanisms of graphene oxide behavioral and morphological changes in zebrafish. Environ. Sci. Pollut. Res. 2019, 26, 30508-30523. [CrossRef]

47. Clemente, Z.; Castro, V.L.; Franqui, L.S.; Silva, C.A.; Martinez, D.S.T. Nanotoxicity of graphene oxide: Assessing the influence of oxidation debris in the presence of humic acid. Environ. Pollut. 2017, 225, 118-128. [CrossRef]

48. Franqui, L.S.; De Farias, M.A.; Portugal, R.V.; Costa, C.A.; Domingues, R.R.; Filho, A.G.S.; Coluci, V.R.; Leme, A.F.P.; Martinez, D.S.T. Interaction of graphene oxide with cell culture medium: Evaluating the fetal bovine serum protein corona formation towards in vitro nanotoxicity assessment and nanobiointeractions. Mater. Sci. Eng. C 2019, 100, 363-377. [CrossRef]

49. Emadi, F.; Amini, A.; Gholami, A.; Ghasemi, Y. Functionalized graphene oxide with chitosan for protein nanocarriers to protect against enzymatic cleavage and retain collagenase activity. Sci. Rep. 2017, 7, 42258. [CrossRef]

50. Mudunkotuwa, I.A.; Grassian, V.H. Biological and environmental media control oxide nanoparticle surface composition: The roles of biological components (proteins and amino acids), inorganic oxyanions and humic acid. Environ. Sci. Nano 2015, 2, 429-439. [CrossRef]

51. Jiang, Y.; Raliya, R.; Fortner, J.D.; Biswas, P. Graphene oxides in water: Correlating morphology and surface chemistry with aggregation behavior. Environ. Sci. Technol. 2016, 50, 6964-6973. [CrossRef]

52. Lowry, G.V.; Hill, R.J.; Harper, S.; Rawle, A.F.; Hendren, C.O.; Klaessig, F.; Nobbmann, U.; Sayre, P.; Rumble, J. Guidance to improve the scientific value of zeta-potential measurements in nanoEHS. Environ. Sci. Nano 2016, 3, 953-965. [CrossRef]

53. Bhattacharya, K.; Mukherjee, S.P.; Gallud, A.; Burkert, S.C.; Bistarelli, S.; Bellucci, S.; Bottini, M.; Star, A.; Fadeel, B. Biological interactions of carbon-based nanomaterials: From coronation to degradation. Nanomed. Nanotechnol. Biol. Med. 2016, 12, 333-351. [CrossRef] [PubMed]

54. Li, D.; Zhang, W.; Yu, X.; Wang, Z.; Su, Z.; Wei, G. When biomolecules meet graphene: From molecular level interactions to material design and applications. Nanoscale 2016, 8, 19491-19509. [CrossRef] [PubMed]

55. Bian, Y.; Bian, Z.; Zhang, J.-X.; Ding, A.-Z.; Liu, S.-L.; Wang, H. Effect of the oxygen-containing functional group of graphene oxide on the aqueous cadmium ions removal. Appl. Surf. Sci. 2015, 329, 269-275. [CrossRef]

56. Liu, X.; Ma, R.; Wang, X.; Ma, Y.; Yang, Y.; Zhuang, L.; Zhang, S.; Jehan, R.; Chen, J.; Wang, X. Graphene oxide-based materials for efficient removal of heavy metal ions from aqueous solution: A review. Environ. Pollut. 2019, 252, 62-73. [CrossRef] [PubMed]

57. Liu, Y.; Chen, M.; Jiang, L.X.; Song, L. New insight into molecular interaction of heavy metal pollutant-Cadmium (II) with human serum albumin. Environ. Sci. Pollut. Res. 2014, 21, 6994-7005. [CrossRef]

58. Seredych, M.; Mikhalovska, L.; Mikhalovsky, S.; Gogotsi, Y. Adsorption of bovine serum albumin on carbon-based materials. C J. Carbon Res. 2018, 4,3. [CrossRef]

59. Sanchís, J.; Olmos, M.; Vincent, P.; Farré, M.; Barceló, D. New insights on the influence of organic co-contaminants on the aquatic toxicology of carbon nanomaterials. Environ. Sci. Technol. 2015, 50, 961-969. [CrossRef]

60. Montagner, A.; Bosi, S.; Tenori, E.; Bidussi, M.; Alshatwi, A.A.; Tretiach, M.; Prato, M.; Syrgiannis, Z. Ecotoxicological effects of graphene-based materials. 2D Mater. 2016, 4, 012001. [CrossRef]

61. Lv, X.; Yang, Y.; Tao, Y.; Jiang, Y.; Chen, B.; Zhu, X.; Cai, Z.; Li, B. A mechanism study on toxicity of graphene oxide to Daphnia magna: Direct link between bioaccumulation and oxidative stress. Environ. Pollut. 2018, 234, 953-959. [CrossRef]

62. Zhao, J.; Wang, Z.; White, J.C.; Xing, B. Graphene in the aquatic environment: Adsorption, dispersion, toxicity and transformation. Environ. Sci. Technol. 2014, 48, 9995-10009. [CrossRef] 
63. Ren, X.; Li, J.; Chen, C.; Gao, Y.; Chen, D.; Su, M.; Alsaedi, A.; Hayat, T. Graphene analogues in aquatic environments and porous media: Dispersion, aggregation, deposition and transformation. Environ. Sci. Nano 2018, 5, 1298-1340. [CrossRef]

64. Castro, V.L.; Clemente, Z.; Jonsson, C.; Silva, M.; Vallim, J.H.; De Medeiros, A.M.Z.; Martinez, D.S.T. Nanoecotoxicity assessment of graphene oxide and its relationship with humic acid. Environ. Toxicol. Chem. 2018, 37, 1998-2012. [CrossRef] [PubMed]

65. Zhang, Y.; Meng, T.; Shi, L.; Guo, X.; Si, X.; Yang, R.; Quan, X. The effects of humic acid on the toxicity of graphene oxide to Scenedesmus obliquus and Daphnia magna. Sci. Total. Environ. 2019, 649, 163-171. [CrossRef] [PubMed]

66. Zhang, H.; Reynolds, M. Cadmium exposure in living organisms: A short review. Sci. Total. Environ. 2019, 678, 761-767. [CrossRef]

67. Yang, J.H.; Kim, H.J.; Lee, S.M.; Kim, B.-M.; Seo, Y.R. Cadmium-induced biomarkers discovery and comparative network analysis in Daphnia magna. Mol. Cell. Toxicol. 2017, 13, 327-336. [CrossRef]

68. Fan, W.-H.; Tang, G.; Zhao, C.-M.; Duan, Y.; Zhang, R. Metal accumulation and biomarker responses in daphnia magna following cadmium and zinc exposure. Environ. Toxicol. Chem. 2009, 28, 305-310. [CrossRef]

69. Qu, R.-J.; Wang, X.-H.; Feng, M.-B.; Li, Y.; Liu, H.-X.; Wang, L.-S.; Wang, Z.-Y. The toxicity of cadmium to three aquatic organisms (Photobacterium phosphoreum, Daphnia magna and Carassius auratus) under different pH levels. Ecotoxicol. Environ. Saf. 2013, 95, 83-90. [CrossRef]

70. Penttinen, S.; Kostamo, A.; Kukkonen, J.V.K. Combined effects of dissolved organic material and water hardness on toxicity of cadmium to Daphnia magna. Environ. Toxicol. Chem. 1998, 17, 2498-2503. [CrossRef]

71. Lin, H.; Xia, X.; Jiang, X.; Bi, S.; Wang, H.; Zhai, Y.; Wen, W.; Guo, X. Bioavailability of pyrene associated with different types of protein compounds: Direct evidence for its uptake by Daphnia magna. Environ. Sci. Technol. 2018, 52, 9851-9860. [CrossRef]

72. De Melo, C.B.; Côa, F.; Alves, O.L.; Martinez, D.S.T.; Barbieri, E. Co-exposure of graphene oxide with trace elements: Effects on acute ecotoxicity and routine metabolism in Palaemon pandaliformis (shrimp). Chemosphere 2019, 223, 157-164. [CrossRef]

73. Markiewicz, M.; Kumirska, J.; Lynch, I.; Matzke, M.; Köser, J.; Bemowsky, S.; Docter, D.; Stauber, R.H.; Westmeier, D.; Stolte, S. Changing environments and biomolecule coronas: Consequences and challenges for the design of environmentally acceptable engineered nanoparticles. Green Chem. 2018, 20, 4133-4168. [CrossRef]

74. Khan, L.U.; Petry, R.; Paula, A.J.; Knobel, M.; Martinez, D.S.T. Protein corona formation on magnetic nanoparticles conjugated with luminescent europium complexes. ChemNanoMat 2018, 4, 1202-1208. [CrossRef]

75. Chetwynd, A.J.; Lynch, I. The rise of the nanomaterial metabolite corona, and emergence of the complete corona. Environ. Sci. Nano 2020, 7, 1041-1060. [CrossRef]

76. Nasser, F.; Lynch, I. Secreted protein eco-corona mediates uptake and impacts of polystyrene nanoparticles on Daphnia magna. J. Proteom. 2016, 137, 45-51. [CrossRef] [PubMed]

77. Mattsson, K.; Aguilar, R.; Torstensson, O.; Perry, D.; Bernfur, K.; Linse, S.; Hansson, L.-A.; Åkerfeldt, K.S.; Cedervall, T. Disaggregation of gold nanoparticles by Daphnia magna. Nanotoxicology 2018, 12, 885-900. [CrossRef]

78. Briffa, S.M.; Nasser, F.; Valsami-Jones, E.; Lynch, I. Uptake and impacts of polyvinylpyrrolidone (PVP) capped metal oxide nanoparticles on Daphnia magna: Role of core composition and acquired corona. Environ. Sci. Nano 2018, 5, 1745-1756. [CrossRef]

79. Grintzalis, K.; Lawson, T.N.; Nasser, F.; Lynch, I.; Viant, M.R. Metabolomic method to detect a metabolite corona on amino-functionalized polystyrene nanoparticles. Nanotoxicology 2019, 13, 783-794. [CrossRef]

80. Martinez, D.S.T.; Paula, A.J.; Fonseca, L.C.; De Luna, L.A.; Silveira, C.P.; Durán, N.; Alves, O.L. Monitoring the hemolytic effect of mesoporous silica nanoparticles after human blood protein corona formation. Eur. J. Inorg. Chem. 2015, 2015, 4595-4602. [CrossRef]

81. Nasser, F.; Constantinou, J.; Lynch, I. Nanomaterials in the environment acquire an "eco-corona" impacting their toxicity to daphnia magna-A call for updating toxicity testing policies. Proteomics 2019, 20, e1800412. [CrossRef]

(C) 2020 by the authors. Licensee MDPI, Basel, Switzerland. This article is an open access article distributed under the terms and conditions of the Creative Commons Attribution (CC BY) license (http://creativecommons.org/licenses/by/4.0/). 